\title{
Оптимизация структурных и ростовых параметров метаморфных InGaAs-фотопреобразователей, полученных методом МOC-гидридной эпитаксии
}

\author{
() Д.В. Рыбальченко, С.А. Минтаиров, Р.А. Салий, Н.Х. Тимошина, \\ М.3. Шварц, Н.А. Калюжный \\ Физико-технический институт им. А.Ф. Иоффе Российской академии наук, \\ 194021 Санкт-Петербург, Россия \\ ฯ E-mail: nickk@mail.ioffe.ru
}

(Получена 20 апреля 2016 г. Принята к печати 26 апреля 2016 г.)

\begin{abstract}
Методом МОС-гидридной эпитаксии созданы метаморфные $\mathrm{Ga}_{0.76} \operatorname{In}_{0.24} \mathrm{As}$-гетероструктуры фотопреобразователей на подложках $n$-GaAs. Обнаружено, что из-за разрыва валентных зон на гетерогранице $p$ - $\mathrm{In}_{0.24} \mathrm{Al}_{0.76} \mathrm{As} / p$ - $\mathrm{In}_{0.24} \mathrm{Ga}_{0.76} \mathrm{As}$ (широкозонное окно/эмиттер) возникает потенциальный барьер для дырок вследствие технологической сложности создания высокой концентрации активной примеси в широкозонном материале. Использование четверного твердого раствора InAlGaAs с содержанием $\mathrm{Al}<40 \%$ позволило повысить концентрацию акцепторов в широкозонном окне до $\sim 9 \cdot 10^{18} \mathrm{~cm}^{-3}$ и полностью нивелировать потенциальный барьер, тем самым уменьшив последовательное сопротивление прибора. Произведен расчет параметров метаморфного буфера GaInAs со ступенчатым профилем изменения содержания In, и оптимизированы параметры его эпитаксиального роста, что позволило улучшить собирание носителей заряда из области $n$-GaInAs и получить квантовую эффективность фотоответа на длине волны 1064 нм $83 \%$. Фотопреобразователи, созданные на основе метаморфных гетероструктур с оптимизированными слоями широкозонного окна и метаморфного буфера, имели кпд преобразования излучения с длиной волны 1064 нм на уровне $38.5 \%$.
\end{abstract}

DOI: 10.21883/FTP.2017.01.44002.8288

\section{1. Введение}

В последнее время существенно вырос интерес к фотопреобразователям (ФП) лазерного излучения (ЛИ) с различной длиной волны. Создание приборов данного класса является актуальной задачей в сфере систем коммуникации, систем беспроводной передачи энергии [1,2] и данных для обеспечения доступа к глобальной сети Интернет в труднодоступных районах и развивающихся странах [3].

Наиболее исследованными являются ФП ЛИ с длиной волны 809 нм, созданные на основе GaAs. Согласование параметров решетки структуры и подложки позволяет достигать высокого кристаллического совершенства и получать значения эффективности, наиболее близкие к теоретическим. Простая модель, не учитывающая ряд потерь в структуре, дает теоретическое значение кпд преобразования ЛИ для GaAs-ФП 78\% [4]. При этом на сегодняшний день наилучшие значения эффективности ФП ЛИ на основе GaAs, полученные на практике, находятся в районе $55-60 \%[5,6]$.

Однако наибольший интерес для беспроводных систем связи представляет собой ЛИ на 1064 нм. В беспроводной паре, где мощный лазер находится на Земле/летательном аппарате, а ФП на принимающей стороне. Несущей средой выступает атмосфера, поэтому разумным при выборе лазера будет оптимум мощности и потерь в атмосфере. Для такого применения хорошо подходит распространенный твердотельный $\mathrm{Nd}$ : YAG-лазер, имеющий мощную моду излучения на длине волны 1064 нм. Согласно солнечным спектрам AM0 и AM1.5 [7], на длине волны 1064 нм разница между космическим и наземным спектрами составляет $<8 \%$. В настоящее время существует промышленное производство фотодетекторов данного ЛИ для систем передачи информации [8]. Однако разработка гетероструктур ФП, служащих для передачи энергии ЛИ на 1064 нм и обладающих высоким значением кпд, остается актуальной задачей.

Одним из возможных вариантов создания ФП ЛИ на 1064 нм могла бы служить структура на основе твердого раствора $\mathrm{Ga}_{0.20} \mathrm{In}_{0.80} \mathrm{P}_{0.54} \mathrm{As}_{0.46}$, выращенная на подложке InP [9]. Однако в данной системе материалов наблюдаются технологические сложности с ростом четверных твердых растворов с двумя компонентами V группы, в которых наблюдается спинодальный распад в области указанного состава [10].

Наиболее простым решением для создания ФП ЛИ на 1064 нм является кремний. Рекордный кпд преобразования ЛИ с длиной волны 1064 нм для гетероструктур на основе кремния находится вблизи 40\% [11]. Однако этот результат был получен при использовании очень сложной процедуры текстурирования поверхности. Более того, максимальные значения кпд были достигнуты при концентрации ЛИ $<1.5 \mathrm{BT} / \mathrm{cm}^{2}$, что недостаточно для сетей беспроводной передачи энергии, а невысокая подвижность носителей не позволяет использовать $\mathrm{Si}$ для изготовления ФП частотно-модулированного ЛИ.

В данной работе разработан ФП для ЛИ с длиной волны 1064 нм на основе метаморфных $\operatorname{In}_{x} \mathrm{Ga}_{1-x} \mathrm{As}-$ гетеро- 

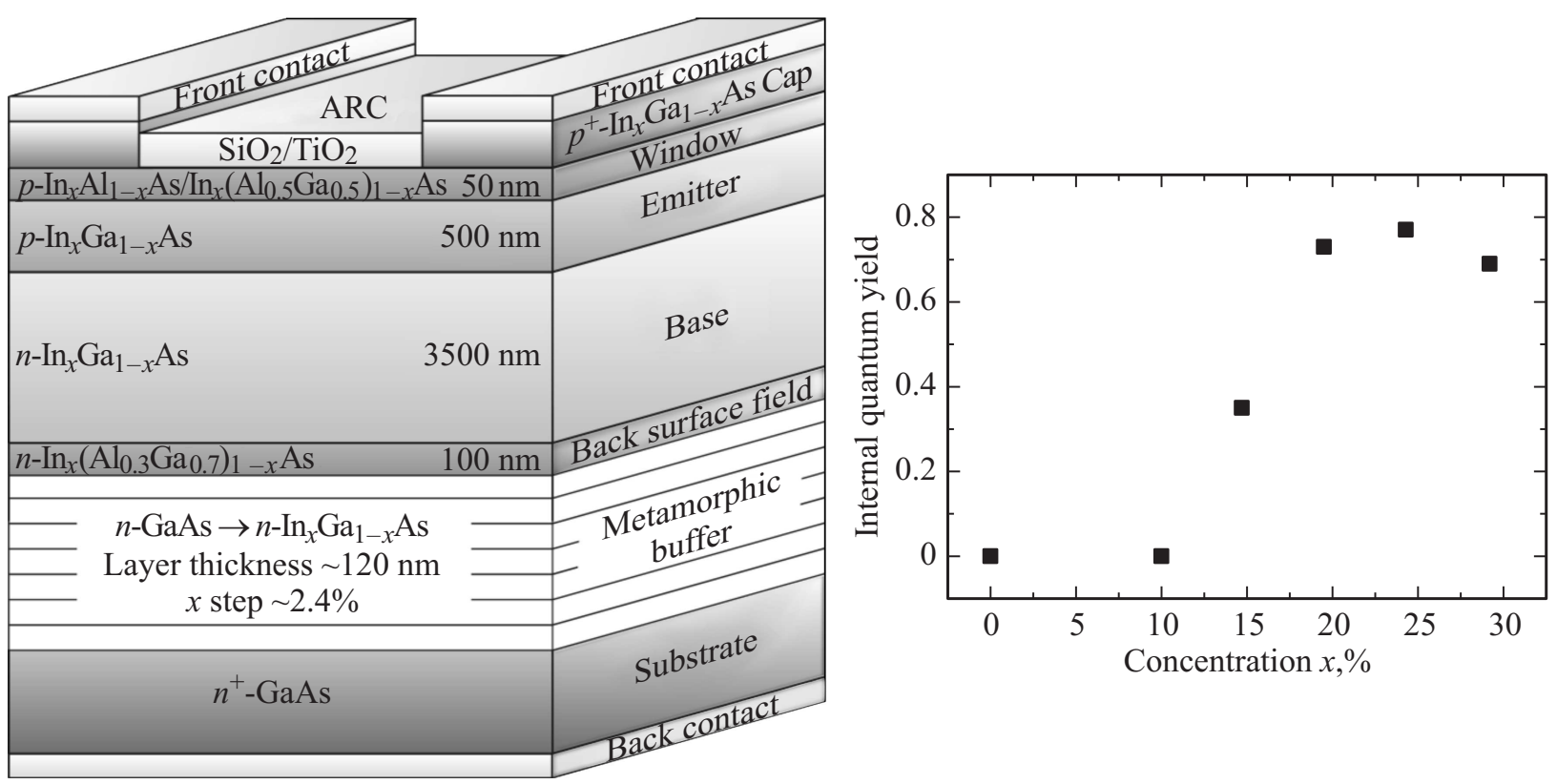

Рис. 1. Схематичное изображение поперечного сечения метаморфного $\operatorname{In}_{x} \mathrm{Ga}_{1-x} \mathrm{As}-Ф П$ (слева) и зависимость внутреннего квантового выхода на длине волны 1064 нм от концентрации индия в ФП (справа).

структур, выращенных методом МОС-гидридной эпитаксии (газофазной эпитаксии из металлоорганических соединений) на достаточно дешевых и распространенных GaAs-подложках. Данный твердый раствор подходит для создания ФП ЛИ как для систем беспроводной передачи энергии, так и для высокочастотных систем коммуникации. Однако из-за рассогласования слоев $\mathrm{Ga}_{1-x} \mathrm{In}_{x} \mathrm{As}$ и подложки GaAs по постоянным решетки создание таких структур возможно только с использованием метаморфного буфера (МБ).

Эпитаксиальный рост структур через метаморфный буфер успешно применяется при создании широкого спектра полупроводниковых приборов, например, транзисторов с высокой подвижностью носителей (mHEMT), лазеров для волоконно-оптических линий связи $[12,13]$. Кроме того, технология метаморфного роста через буферные слои была применена при создании каскадных (многопереходных) гетероструктур ФП солнечного излучения [14]. При этом практически нет опубликованных данных по использованию таких метаморфных гетероструктур в качестве ФП ЛИ.

\section{2. Методика эксперимента}

Метаморфные гетероструктуры ФП выращивались на исследовательской установке МОС-гидридной эпитаксии при пониженном давлении 100 мбар на подложках $n$-GaAs (100) диаметром 50 мм, разориентированных на $6^{\circ}$ в направлении [111]. Рост эпитаксиальных фотоактивных слоев проводился при температуре $700^{\circ} \mathrm{C}$, скорости роста порядка 3 мкм/ч и соотношении атомов $\mathrm{V}$ и III групп в газовой фазе, равном 30. Экспериментальные исследования по росту слоев метаморфного буфера осуществлялись в диапазоне температур $550-700^{\circ} \mathrm{C}$ и скоростей роста $1.5-6$ мкм/ч. В качестве источников элементов III группы использовались металлоорганические соединения: триметилгаллий (TMGa), триметилалюминий (TMAl), триметилиндий (TMIn). Арсин $\left(\mathrm{AsH}_{3}\right)$ использовался в качестве источника мышьяка. Для легирования слоев с целью получения $n$-типа проводимости применялся моносилан $\left(\mathrm{SiH}_{4}\right)$, а источником легирующей примеси для слоев $p$-типа проводимости был диэтилцинк (DEZn).

Структура ФП, выращенная на метаморфном буфере, включала $p-n$-диод с фотооактивными областями базы (n-типа проводимости) и эмиттера ( $p$-типа), а также функциональные слои: тыльный потенциальный барьер и широкозонное окно (рис. 1, слева). Толщины базы и эмиттера ФП задавались из расчета полного поглощения для GaAs-ФП и составляли 3.5 мкм и $500 \mathrm{Hм}$ соответственно. В качестве слоя широкозонного окна использовались тройной, $\operatorname{In}_{x} \mathrm{Al}_{1-x} \mathrm{As}$, и четверной, $\mathrm{In}_{x}\left(\mathrm{Al}_{0.5} \mathrm{Ga}_{0.5}\right)_{1-x} \mathrm{As}$, твердые растворы. Широкозонное окно не только предотвращает потери „горячих“ носителей на поверхности ФП, но, что не менее важно, выполняет функцию стоп-слоя для ряда селективных химических травителей, применяемых при постростовой обработке ФП на этапе стравливания контактного слоя, не закрытого контактной сеткой.

Изменение концентрации индия $x$ в слоях $\operatorname{In}_{x} \mathrm{Ga}_{1-x} \mathrm{As}$ метаморфного буфера производилось ступенчато с шагом $\sim 2.5 \%$ при толщине каждой „ступени“ 120 нм. Для оценки минимальной толщины буферных слоев в системе InGaAs/GaAs был предварительно проведен 
расчет критических толщин для шага в $2.5 \%$ по модели Мэттьюза-Блэксли [15]. Для этого было численно решено уравнение

$$
h_{c}=\frac{b\left(1-v \cos ^{2} \phi\right)}{8 \pi f(1+v) \sin \phi \cos \theta}\left[\ln \left(\frac{h_{c}}{b \sin \theta}\right)+1\right],
$$

где $\phi=60^{\circ}, \theta=54.74^{\circ}$, коэффициент Пуассона, взятый в приближении изотропного кристалла, равен $v=1 / 3$, вектор Бюргерса $b=a_{0} / \sqrt{2}, f=\left(a_{0}-a_{s}\right) / a_{0}$, а параметры $a_{0}$ и $a_{s}$ равны постоянным решеток слоя и подложки соответственно. Была определена зависимость критической толщины от концентрации In в растущем слое $\operatorname{In}_{x} \mathrm{Ga}_{1-x} \mathrm{As}$ на подложке GaAs, которая подтвердила правильность выбранного шага по составу в слоях МБ. Согласно проведенному расчету, критическая толщина по модели Мэттьюза-Блэксли для шага 2.5\% в системе материалов InGaAs/GaAs составляет $82 \mathrm{Hм}$. Таким образом, шаг по содержанию In в 2-3\% позволяет получить достаточное количество интерфейсов в буфере, на которые могут загибаться дислокации, при сравнительно небольшой критической толщине слоев.

Была создана серия InGaAs-структур с концентрацией индия в фотоактивных областях порядка 10, 14, 19, 24 и $29 \%$ при количестве ступеней постоянного состава в метаморфной буферной области 4, 6, 8, 10 и 12 соответственно.

Для измерения фотовольтаических характеристик ФП на основе выращенных структур методом фотолитографии были изготовлены приборные образцы с размерами $3 \times 3.4$ мм и металлической контактной сеткой с шагом шин 100 мкм. На лицевую сторону структуры ФП напылялось многослойное просветляющее покрытие $\mathrm{SiO}_{2} / \mathrm{TiO}_{2}$ (ARC на рис. $1, a$ ) для минимизации отражения излучения с длиной волны 1064 нм.

Для измерения спектральных зависимостей внешнего квантового выхода фотоответа и коэффициента отражения дополнительно были изготовлены образцы без затенения контактной сеткой для исследования максимального уровня фотоответа и внутреннего квантового выхода. Такие фотодиоды изготавливались по упрощенной постростовой технологии путем электрохимического осаждения никелевых контактов и стравливания контактного слоя.

Запись спектральных зависимостей внешнего квантового выхода фотоответа ФП проводилась на специализированной установке в расширенном диапазоне длин волн до 1400 нм [16]. Полученные значения внешнего квантового выхода фотоответа пересчитывались в единицы токовой спектральной чувствительности $(\mathrm{A} / \mathrm{BT})$. Одновременно проводилась оценка значения спектральной чувствительности при засветке ФП непрерывным лазером с длиной волны излучения 1064 нм. Проведенные двумя независимыми методами измерения спектральной чувствительности ФП для длины волны излучения 1064 нм показали хорошее согласие получаемых данных: 0.68 А/Вт по данным спектральных измерений в сравнении с 0.66 А/Вт при измерении на лазере.
Вольт-амперные характеристики (BАХ) ФП в условиях возрастающей освещенности измерялись с использованием следующего оборудования: 1) имитатор излучения с длительностью светового импульса 1 мкс, что исключало нагрев ФП в процессе измерения; оценка мощности поступающего на ФП излучения оценивалась как $P_{l}=I_{s c} /[\mathrm{SR}]_{1064}$, где $I_{s c}-$ ток короткого замыкания $\Phi П$, измеренный при заданном уровне освещенности, $[\mathrm{SR}]_{1064}$ - значение спектральной чувствительности для длины волны 1064 нм; 2) непрерывный лазер (длина волны излучения 1064 нм) с оптоволоконным выводом и коллиматором для корректировки распределения облученности на ФП; мощность падающего на ФП лазерного излучения контролировалась термоэлектрическим детектором.

Запись ВАХ ФП осуществлялась при равномерной (импульсный имитатор) и частично неравномерной (лазер с коллиматором) освещенности фотоприемной поверхности ФП. Мощность лазерного излучения варьировалась в диапазоне от 0.08 до 1 Вт, что для образца с площадью фоточувствительной поверхности $0.0784 \mathrm{~cm}^{2}$ соответствует плотности мощности ЛИ от 1.3 до $12 \mathrm{BT} / \mathrm{cm}^{2}$.

Для моделирования зонных диаграмм выращенных структур использовалось бесплатное программное обеспечение AFORS-HET [17,18].

Исследования структурных параметров образцов ФП проводились на растровом сканирующем электронном микроскопе (CЭM) CamScan Series 4 DV100. Концентрация носителей заряда для отдельных слоев структуры определялась из эффекта Холла на однослойных тестовых образцах размером $\sim 10 \times 10$ мм.

\section{3. Результаты и обсуждение}

Параметры основных структур, созданных и исследованных в ходе работы, представлены в таблице. В работе [19] были исследованы спектральные зависимости квантового выхода фотоответа фотопреобразователей, созданных на основе серии метаморфных $\mathrm{In}_{x} \mathrm{Ga}_{1-x}$ As-гетероструктур с различной концентрацией индия в фотоактивной области $(10,14,19,24$ и 29\%). Зависимость внутреннего квантового выхода фотоответа на длине волны 1064 нм от концентрации индия $x$ в фотоактивной области ФП показала (рис. 1, справа), что фоточувствительностью на данной длине волны обладают ФП, созданные на основе твердых растворов с $x$ не менее $14 \%$. При этом наибольший фототок

Параметры основных структур $\mathrm{In}_{0.24} \mathrm{Ga}_{0.76} \mathrm{As}-Ф П$

\begin{tabular}{c|c|c}
\hline Структура & Широкозонное окно & $\begin{array}{c}\text { Температура } \\
\text { роста МБ, }{ }^{\circ} \mathrm{C}\end{array}$ \\
\hline $\mathrm{A}$ & $\mathrm{In}_{0.24} \mathrm{Al}_{0.76} \mathrm{As}$ & 700 \\
$\mathrm{~B}$ & $\mathrm{In}_{0.24}\left(\mathrm{Al}_{0.5} \mathrm{Ga}_{0.5}\right)_{0.76} \mathrm{As}$ & 700 \\
$\mathrm{C}$ & $\mathrm{In}_{0.24}\left(\mathrm{Al}_{0.5} \mathrm{Ga}_{0.5}\right)_{0.76} \mathrm{As}$ & 600
\end{tabular}

Физика и техника полупроводников, 2017, том 51, вып. 1 


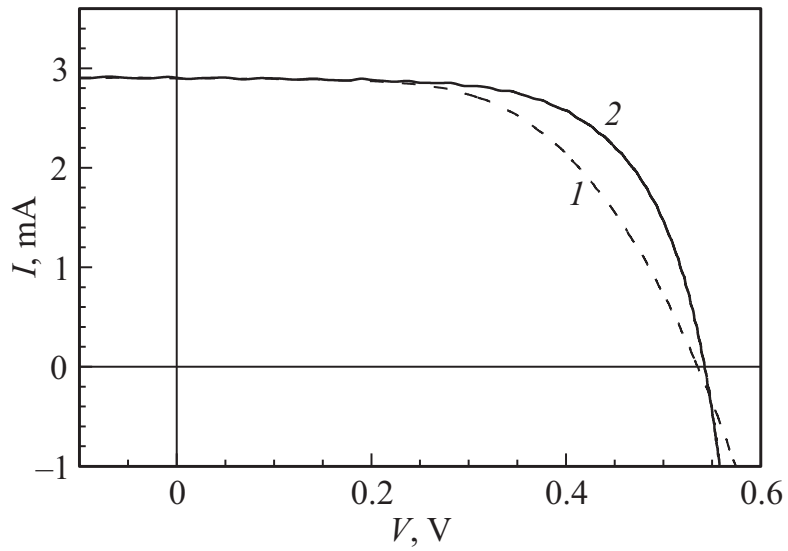

Pис. 2. $\mathrm{BAX}$ метаморфных $\mathrm{In}_{0.24} \mathrm{Ga}_{0.76} \mathrm{As}-Ф П$ при освещении спектром AM1.5 (1, „солнце“): структуры А (1) и В (2).

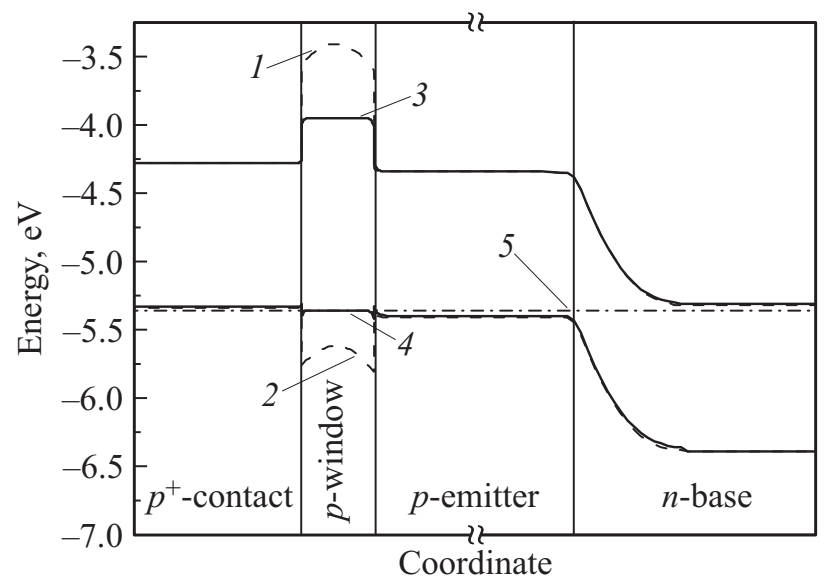

Рис. 3. Зонные диаграммы различных структур метаморфных $\mathrm{In}_{0.24} \mathrm{Ga}_{0.76} \mathrm{As}-Ф П: 1,3$ - дно зоны проводимости структур А, В соответственно; 2, 4 - потолок валентной зоны структур А, В соответственно; 5 - уровень Ферми. Диаграммы составлены с помощью программы AFORS-HET.

генерирует ФП с $x=24 \%$, квантовая эффективность которого на данной длине волны была на уровне $\sim 80 \%$.

Таким образом, ФП с фотоактивной областью на основе твердого раствора $\mathrm{In}_{0.24} \mathrm{Ga}_{0.76} \mathrm{As}$ (структура A см. таблицу) можно считать наиболее подходящим для преобразования ЛИ с длиной волны 1064 нм.

Однако световые $\mathrm{BAX} I(V)$ фотопреобразователей, созданных на основе как твердого раствора $\mathrm{In}_{0.24} \mathrm{Ga}_{0.76} \mathrm{As}$, так и других составов, характеризовались большим последовательным сопротивлением (рис. 2, кривая 1). Это может являться следствием наличия потенциального барьера для основных носителей заряда в структуре $Ф П$.

Было проведено моделирование зонной диаграммы гетероструктуры $\mathrm{In}_{0.24} \mathrm{Ga}_{0.76}$ As-ФП при помощи программного пакета AFORS-HET (рис. 3). Обнаружено, что на гетероинтерфейсе окно/эмиттер присутствует потенциальный барьер для дырок, вызванный разрывом валентных зон на границе $\operatorname{In}_{0.24} \mathrm{Al}_{0.76} \mathrm{As}_{\mathrm{s}} / \mathrm{In}_{0.24} \mathrm{Ga}_{0.76} \mathrm{As}$ (рис. 3, кривая 2). В слое широкозонного окна $\mathrm{In}_{0.24} \mathrm{Al}_{0.76} \mathrm{As}$ уровень Ферми существенно отступает от потолка валентной зоны. Подобный вид зонной диаграммы связан с низким уровнем легирования широкозонного окна по сравнению с эмиттером и контактным слоем. Легирование широкозонных полупроводниковых слоев, например, $\mathrm{AlGaAs}$ в в эпитаксиальном процессе имеет известную специфическую особенность, которая состоит в том, что в данных растворах с концентрацией $\mathrm{Al}>22 \%$ атомы легирующей примеси с большой вероятностью встраиваются в кристаллическую решетку как глубокие центры. При увеличении легирования происходит насыщение концентрации электрически активной примеси в узлах решетки. Измерения эффекта Холла тестовых слоев $p$ - $\operatorname{In}_{0.24} \mathrm{Al}_{0.76} \mathrm{As}: \mathrm{Zn}$, использованных в гетероструктурах ФП ЛИ в качестве широкозонного окна, показали, что данные твердые растворы обладают аналогичной особенностью. Достигнуть концентрации акцепторной примеси выше значения $\sim 5 \cdot 10^{17} \mathrm{~cm}^{-3}$ не удалось. В результате тонкий слой $p$ - $\mathrm{In}_{0.24} \mathrm{Al}_{0.76} \mathrm{As}: \mathrm{Zn}$ широкозонного окна с невысокой концентрацией активной примеси создает потенциальный барьер для транспорта основных носителей заряда. Оценочная величина барьера составляет $>0.4$ эВ.

Для устранения потенциального барьера в качестве широкозонного окна был предложен более узкозонный материал, сформированный за счет введения в подрешетку III группы атомов Ga с концентрацией, равной концентрации атомов Al (структура B, - cм. таблицу). Исследование эффекта Холла тестовых слоев $p$ - $\mathrm{In}_{0.24}\left(\mathrm{Al}_{0.5} \mathrm{Ga}_{0.5}\right)_{0.76} \mathrm{As}: \mathrm{Zn}$ показало значительное увеличение степени вхождения электрически активной примеси в данный твердый раствор, что позволило добиться холловской концентрации $\sim 9 \cdot 10^{18} \mathrm{~cm}^{-3}$. Как видно из зонной диаграммы (рис. 3 , кривая 4 ), использование узкозонного материала $p$ - $\operatorname{In}_{0.24}\left(\mathrm{Al}_{0.5} \mathrm{Ga}_{0.5}\right)_{0.76} \mathrm{As}: \mathrm{Zn} \quad \mathrm{c}$ высокой концентрацией акцепторов позволяет полностью устранить потенциальный барьер на гетерогранице эмиттер/широкозонное окно.

Однако при выборе состава широкозонного окна для ФП необходимо учитывать, что этот слой также выполняет функцию стоп-слоя при травлении контактного слоя с незакрытой контактной сеткой фоточувствительной поверхности во время изготовления ФП с использованием фотолитографии. Известно, что при травлении, например, слоев $\mathrm{AlGaAs}$ приемлемая селективность к химическим травителям появляется при концентрациях алюминия $>45 \%$. В данном случае, несмотря на существенное уменьшение концентрации алюминия в слое окна до абсолютных $38 \%$, состав $\operatorname{In}_{0.24}\left(\mathrm{Al}_{0.5} \mathrm{Ga}_{0.5}\right)_{0.76} \mathrm{As}$ выполнял функцию стоп-слоя при использовании травителя $\mathrm{H}_{2} \mathrm{O}_{2}: \mathrm{C}_{6} \mathrm{H}_{8} \mathrm{O}_{7}=1: 1$. Вероятно, наличие индия в твердом растворе позволяет повысить селективность. Для подтверждения данного факта фотопреобразователи, изготовленные из выращенных структур с использованием электрохимического осаждения никелевых кон- 


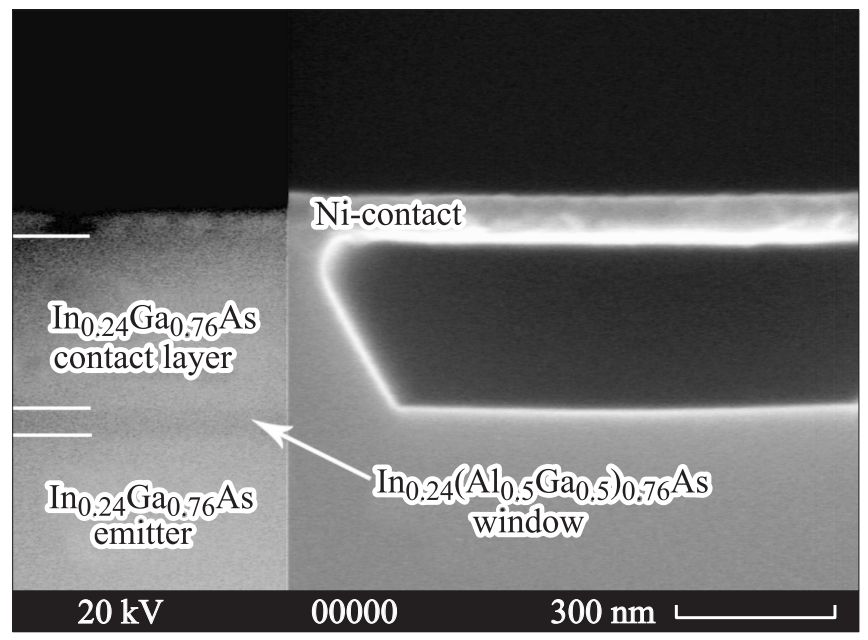

Рис. 4. СЭМ-изображение поперечного скола $\mathrm{In}_{0.24} \mathrm{Ga}_{0.76} \mathrm{As}-Ф П$, подтверждающее селективность травления контактного слоя с поверхности широкозонного окна $\mathrm{In}_{0.24}\left(\mathrm{Al}_{0.5} \mathrm{Ga}_{0.5}\right)_{0.76} \mathrm{As}$ (структура B).

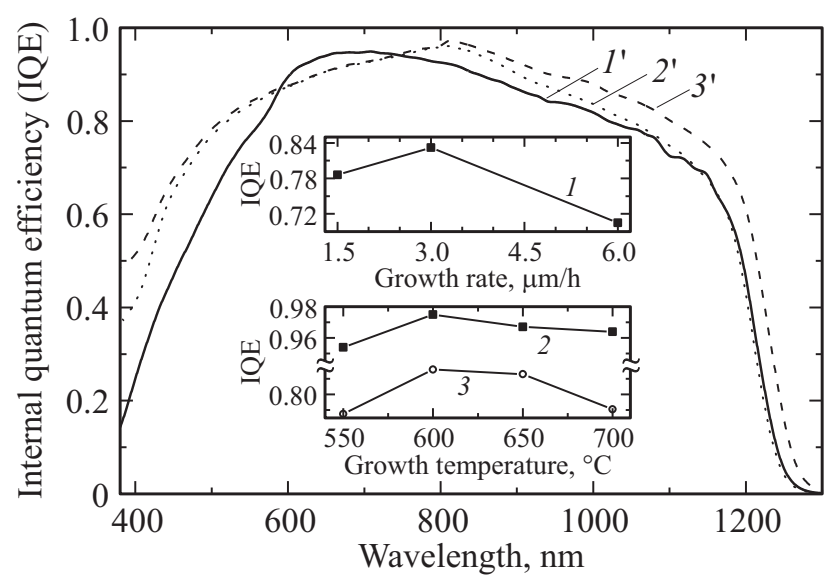

Рис. 5. Спектры внутреннего квантового выхода $\mathrm{In}_{0.24} \mathrm{Ga}_{0.76}$ As-ФП. Структуры: $1^{\prime}-\mathrm{A}, 2^{\prime}-\mathrm{B}, 3^{\prime}-\mathrm{C}$. На вставках: зависимость внутреннего квантового выхода на длине волны 1064 нм от скорости роста метаморфного буфера (при температуре роста $600^{\circ} \mathrm{C}$ ) (1), зависимость максимального внутреннего квантового выхода от температуры роста метаморфного буфера (2), зависимость внутреннего квантового выхода на длине волны 1064 нм от температуры роста метаморфного буфера (3).

тактов и стравливания контактного слоя, были исследованы с помощью СЭМ. Изображение поперечного сечения образца ФП (рис. 4) после травления наглядно подтверждает селективность выбранного травителя к данному составу широкозонного окна.

Изменение состава широкозонного окна существенным образом повлияло на спектральные и электрические характеристики изготовленных ФП. Значительно изменилось дифференциальное сопротивление вблизи точки напряжения холостого хода $V_{o c}$ (рис. 2, кривая 2), а также возрос фактор заполнения ВАХ. Это экспериментально подтверждает гипотезу, что большое последовательное сопротивление исходной гетероструктуры было связано с потенциальным барьером на гетерогранице окно/эмиттер, при этом уменьшение ширины запрещенной зоны материала окна с одновременным увеличением его уровня легирования позволило устранить этот барьер.

На спектральной характеристике ФП появился максимум, соответствующий ширине запрещенной зоны $\mathrm{In}_{0.24}\left(\mathrm{Al}_{0.5} \mathrm{Ga}_{0.5}\right)_{0.76} \mathrm{As}$ (рис. 5, кривая $\left.2^{\prime}\right)$. Несмотря на уменьшение ширины запрещенной зоны широкозонного окна и связанное с этим некоторое падение квантового выхода фотоответа в диапазоне длин волн 600-750 нм, общее значение фототока, генерированного за счет поглощения коротковолновых фотонов, возросло. Это можно объяснить более эффективным собиранием носителей, генерированных в верхних слоях гетероструктуры, вызванным улучшением кристаллического качества гетерограницы окно/эмиттер при уменьшении концентрации алюминия.

Однако величина квантового выхода фотоответа в длинноволновой области изменилась незначительно. В частности, значение квантовой эффективности на целевой длине волны 1064 нм составило 78\% (и 77\% в исходном образце). Слабое собирание носителей заряда в длинноволновой области определяется низким значением их диффузионных длин в базовом слое $n$-InGaAs, что характерно для метаморфных гетероструктур и вызвано прорастанием дислокаций из метаморфного буфера [20].

Степень прорастания дислокаций через метаморфный буфер в фотоактивные слои определяется параметрами метаморфного буфера - толщиной и числом составляющих его слоев постоянного состава, а также температурой и скоростью роста буферных слоев. Поскольку толщина и число „ступеней“ МБ были выбраны исходя из расчетных данных, то для уменьшения концентрации прорастающих в область базы дислокаций и более эффективного собирания носителей заряда, генерированных излучением с длиной волны 1064 нм, была проведена серия по оптимизации параметров роста МБ.

Температура роста как МБ, так и остальных слоев исходной структуры составляла $700^{\circ} \mathrm{C}$, поскольку данная температура соответствует диффузионному МОС-гидридному режиму роста кристаллов для ряда арсенидных твердых растворов [21]. Однако, так как релаксация упругих напряжений и образование дислокаций несоответствия являются температурно-зависимыми процессами, были выращены гетероструктуры ФП, метаморфный буфер которых выращивался при пониженной температуре: 650,600 и $550^{\circ} \mathrm{C}$. Скорость роста МБ при этом варьировалась в диапазоне 1.5-6 мкм/ч.

Наибольшее значение квантового выхода фотоответа на длине волны 1064 нм было достигнуто при скорости роста МБ 3 мкм/ч (рис. 5, верхняя вставка, кривая 1) и температуре роста МБ $600^{\circ} \mathrm{C}$ (рис. 5, нижняя вставка, кривая 3). Понижение температуры роста МБ до $550^{\circ} \mathrm{C}$ при неизменной скорости роста (3 мкм/ч) привело к 


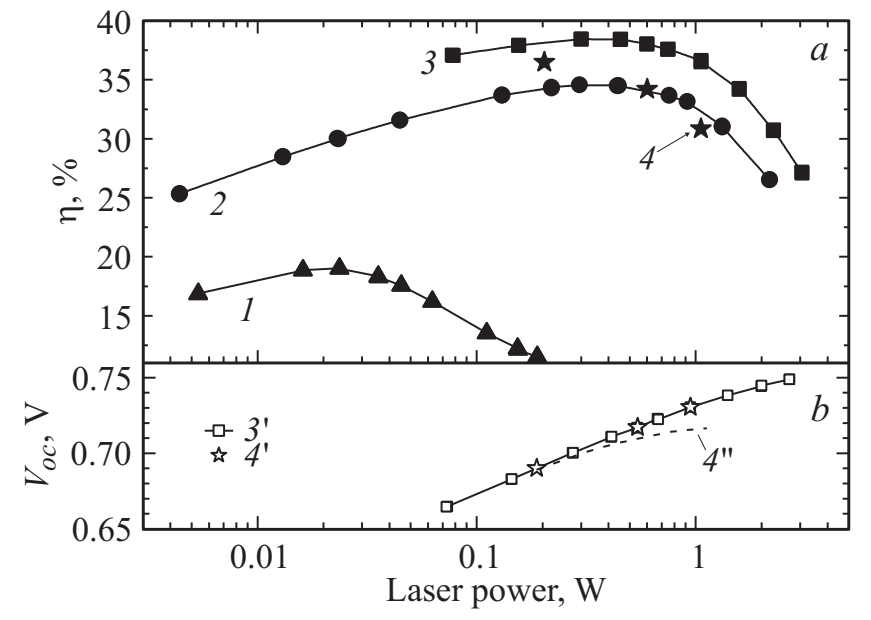

Рис. 6. Мощностные зависимости электрофизических характеристик структур $\mathrm{In}_{0.24} \mathrm{Ga}_{0.76}$ As-ФП: $a$ - кпд преобразования $(\eta)$ ЛИ с длиной волны 1064 нм для структур А (1), В (2), С (3) при равномерном распределении освещенности, и для структуры $\mathrm{C}$, при частично неравномерном освещении ЛИ с учетом температурной коррекции (4). $b$ - напряжение холостого хода $V_{\text {oc }}$ для структуры С при равномерном $\left(3^{\prime}\right)$, частично неравномерном (лазерный луч) $\left(4^{\prime \prime}\right)$, частично неравномерном, с учетом температурной коррекции $\left(4^{\prime}\right)$ распределении освещенности на фотоприемной поверхности образца.

ухудшению спектральной характеристики (рис. 5, нижняя вставка, кривые 2,3). При данной температуре скорость миграции адатомов по поверхности образца резко уменьшается, поэтому при неизменной скорости доставки компонент в зону роста качество роста снижается, что проявляется в усилении волнообразного рельефа поверхности, как было показано в [19].

В результате оптимизации параметров роста МБ (температура роста $600^{\circ} \mathrm{C}$, скорость роста $3 \mathrm{M \kappa м/ч;}$ структура С - см. таблицу) значение эффективности фотоответа на длине 1064 нм возросло до $83 \%$ (рис. 5, кривая $3^{\prime}$ ).

Таким образом, оптимизация параметров широкозонного окна и МБ гетероструктуры привела к улучшению электрических и спектральных характеристик InGaAs-ФП, что позволило достичь кпд преобразования ЛИ с длиной волны 1064 нм 38.5\% при равномерном освещении имитатором солнечного излучения (рис. 6, кривая 3). Плотность мощности падающего излучения, при которой достигнут максимальный кпд, составила $\sim 5 \mathrm{BT} / \mathrm{cm}^{2}$.

При облучении ФП лазером Nd:YAG (неравномерное освещение) с непрерывной модой излучения на длине волны 1064 нм наблюдался неконтролируемый нагрев образца, приводящий к снижению регистрируемых значений напряжения холостого хода $V_{o c}$ (рис. 6 , кривая $\left.4^{\prime \prime}\right)$. Охлаждение ФП на 5 и $10^{\circ} \mathrm{C}$ для условий облучения потоком ЛИ мощностью 0.6 и 1 Вт соответственно обеспечило подъем $V_{o c}$ до значений, полученных при $25^{\circ} \mathrm{C}$ в условиях импульсной засветки (рис. 6 , кривая $4^{\prime}$ ).
Ход зависимости кпд от мощности ЛИ наглядно свидетельствует о возрастании роли резистивных потерь при переходе к неравномерной освещенности, создаваемой лазерным лучом на ФП (рис. 6, кривая 4). Снижение этих потерь позволяет повысить эффективность преобразования ЛИ, как показали измерния при равномерном освещении имитатором солнечного излучения (рис. 6, кривая 3).

\section{4. Заключение}

Проведены исследования фотопреобразователей лазерного излучения с длиной волны 1064 нм на основе метаморфных $\mathrm{In}_{0.24} \mathrm{Ga}_{0.76} \mathrm{As}-$ гетероструктур, выращенных методом МОС-гидридной эпитаксии на подложках $n$-GaAs.

Проведенный анализ зонной диаграммы ФП, выявивший причину большого последовательного сопротивления гетероструктуры с широкозонным окном $p$ - $\mathrm{In}_{0.24} \mathrm{Al}_{0.76} \mathrm{As}: \mathrm{Zn}$, показал, что из-за разрыва валентных зон на гетероинтерфейсе широкозонное окно/эмиттер возникает потенциальный барьер для основных носителей заряда вследствие технологической сложности создания высокой концентрации активной примеси в широкозонном материале. Использование в качестве широкозонного окна четверного твердого pacтвора InAlGaAs (в котором концентрация Al снижена до значения 38\%) позволило повысить концентрацию носителей в широкозонном окне до $\sim 9 \cdot 10^{18} \mathrm{~cm}^{-3}$. Исследование зонной диаграммы показало, что использование узкозонного материала $p$ - $\operatorname{In}_{0.24}\left(\mathrm{Al}_{0.5} \mathrm{Ga}_{0.5}\right)_{0.76} \mathrm{As}: \mathrm{Zn}$ с высокой концентрацией активной примеси позволяет полностью устранить обнаруженный потенциальный барьер, что было подтверждено экспериментально.

Расчет параметров метаморфного буфера InGaAs со ступенчатым профилем изменения содержания In (количество ступеней и их толщина) и оптимизация параметров его эпитаксиального роста (температура и скорость роста), позволили повысить эффективность собирания носителей заряда из области базы $n$-GaInAs и получить квантовую эффективность фотоответа $83 \%$ на длине волны 1064 нм.

В результате проведенной оптимизации структурных и ростовых параметров метаморфной гетероструктуры ФП получен кпд преобразования ЛИ с длиной волны 1064 нм на уровне $38.5 \%$ (при равномерном освещении и плотности мощности падающего излучения $\left.5 \mathrm{~B} / \mathrm{cm}^{2}\right)$.

Работа выполнена при поддержке Российского научного фонда, соглашение № 14-29-00178.Разработка постростовой технологии изготовления ФП выполнена при поддержке РФФИ (грант № 16-08-0072 А).

Авторы выражают благодарность С.И. Трошкову за проведение СЭМ-измерений, А.А. Усиковой за проведение постростовой обработки структур ФП, а также А.С. Гудовских за полезные обсуждения. 


\section{Список литературы}

[1] https://www.nasa.gov/centers/armstrong/news/FactSheets/ FS-087-DFRC.html

[2] G.A. Landis, M. Stavnes, S. Oleson, J. Bozek. Proc. 28th SAE, ASME, and ASEE Joint Propulsion Conf. Exhibit. (Nashville, USA, 1992) paper AIAA-92-3213.

[3] http://newsroom.fb.com/news/2015/07/new-milestones-inconnectivity-labs-aircraft-and-laser-programs/

[4] V.M. Andreev, V.P. Khvostikov, V.S. Kalinovsky, V.M. Lantratov, V.A. Grilikhes, V.D. Rumyantsev, M.Z. Shvarts, V. Fokanov, A.K. Pavlov. Proc. 3rd World Conf. Photovoltaic Energy Conversion (Osaka, Japan, 2003) p. 761.

[5] http:/www.researchgate.net/profile/Henning_Helmers/ publication/263560972_Photovoltaic_Cells_for_Optical_ Power_and_Data_Transmission/links/0a85e53b3fdbf79 c4d000000.pdf

[6] V. Khvostikov, N. Kalyuzhnyy, S. Mintairov, N. Potapovich, M. Shvarts, S. Sorokina, A. Luque, V. Andreev. AIP Conf. Proc., 1616, 21 (2014).

[7] http://rredc.nrel.gov/solar/spectra/am1.5/

[8] http://www.thorlabs.de/thorproduct.cfm?partnumber=DET10N

[9] Р.В. Левин, А.Е. Маричев, М.З. Шварц, Е.П. Марухина, Б.В. Пушный, М.Н. Мизеров, В.М. Андреев, В.П. Хвостиков. ФТП, 49 (5), 715 (2015).

[10] A.E. Marichev, B.V. Pushnyi, R.V. Levin. J. Phys.: Conf. Ser., 690, 012010 (2016).

[11] M.A. Green, J. Zhao, A. Wang, S.R. Wenham. IEEE Electron Dev. Lett., 13 (6), 317 (1992).

[12] А.Е. Жуков, А.Р. Ковш, С.С. Михрин, Е.С. Семенова, Н.А. Малеев, А.П. Васильев, Е.В. Никитина, Н.В. Крыжановская, А.Г. Гладышев, Ю.М. Шерняков, Ю.Г. Мусихин, М.В. Максимов, Н.Н. Леденцов, В.М. Устинов, Ж.И. Алфёров. ФТП, 37 (9), 1143 (2003).

[13] А.Ю. Егоров, Л.Я. Карачинский, И.И. Новиков, А.В. Бабичев, В.Н. Неведомский, В.Е. Бугров. ФТП, 49 (11), 1569 (2015).

A.Yu. Egorov, L.Ya. Karachinsky, I.I. Novikov, A.V. Babichev, V.N. Nevedomskiy, V.E. Bugrov. Semiconductors, 49 (11), 1522 (2015).

[14] R.M. France, J.F. Geisz, I. Garcia, M.A. Steiner, W.E. McMahon et al. IEEE J. Photovoltaics, 5 (1), 432 (2015).

[15] J.W. Matthews, A.E. Blakeslee. J. Cryst. Growth, 27, 118 (1974).

[16] M.Z. Shvarts, A.E. Chalov, E.A. Ionova, V.R. Larionov, D.A. Malevskiy, V.D. Rumyantsev, S.S. Titkov. Proc. 20th Europ. Photovoltaic Solar Energy Conf. (Barcelona, Spain, 2005) p. 278.

[17] http://www.helmholtz-berlin.de/forschung/oe/ee/si-pv/ projekte/asicsi/afors-het/index_en.html

[18] R. Stangl, M. Kriegel, M. Schmidt. Proc. 4th World Conf. Photovoltaic Energy Conversion (Hawaii, USA, 2006) p. 1350.

[19] С.А. Минтаиров, В.М. Емельянов, Д.В. Рыбальченко, Р.А. Салий, Н.Х. Тимошина, М.З. Шварц, Н.А. Калюжный. ФТП, 50 (4), 525 (2016).

[20] C.L. Andre, A. Khan, M. Gonzalez, M.K. Hudait, E.A. Fitzgerald et.al. Proc. 29th IEEE Photovolt. Spec. Conf. (New Orleans, USA, 2002) p. 1043.

[21] G.B. Stringfellow. Organometallic Vapor-Phase Epitaxy: Theory and Practice, 2nd edn (Academic Press, San Diego, 1999).

Редактор Л.В. Шаронова

\section{Optimization of structural and growth parameters of metamorphic InGaAs photoconverters grown by MOCVD}

\author{
D.V. Rybalchenko, S.A. Mintairov, R.A. Salii, \\ M.Z. Shvarts, N.K. Timoshina, N.A. Kalyuzhnyy \\ loffe Institute, \\ Russian Academy of Sciences, \\ 194021 St. Petersburg, Russia
}

Abstract Metamorphic $\operatorname{In}_{0.24} \mathrm{Ga}_{0.76}$ As heterostructures for photovoltaic converters have been grown by the MOCVD technique. It has been found that due to discontinuity of valence bands at the $p$ - $\operatorname{In}_{0.24} \mathrm{Al}_{0.76} \mathrm{As} / p$ - $\operatorname{In}_{0.24} \mathrm{Ga}_{0.76} \mathrm{As}$ heterointerface (window/emitter) a potential barrier for holes arises as a result of low carrier concentration in the wide-band-gap material. The use of InAlGaAs solid solution with Al concentration of $<40 \%$ allowed raising the holes concentration in the wide-band-gap window, eliminating completely the potential barrier and reducing the device series resistance. Parameters of the InGaAs metamorphic buffer layer with a stepwise profile of In concentration variation were calculated and its epitaxial growth conditions have been optimized, which allowed improving collection of charge carriers from the $n$-InGaAs base region and obtaining the photoresponse quantum yield of $83 \%$ at $1064 \mathrm{~nm}$ wavelength. Optimization of the photovoltaic converter metamorphic heterostructure has resulted in obtaining $1064 \mathrm{~nm}$ laser radiation conversion efficiency at the level of $38.5 \%$. 